\title{
Responses to arsenate stress by Comamonas sp. strain CNB-1 at genetic and proteomic levels
}

\author{
Correspondence \\ Shuang-Jiang Liu \\ liusj@sun.im.ac.cn \\ Si-Qi Liu \\ siqiliu@genomics.org.cn
}

Received 10 July 2007

Revised 13 August 2007

Accepted 15 August 2007

\author{
Yun Zhang, ${ }^{1}$ Ying-Fei Ma, ${ }^{1}$ Su-Wei Oi, ${ }^{1}$ Bo Meng, ${ }^{2}$ \\ Muhammad Tausif Chaudhry, ${ }^{1}$ Si-Oi Liu ${ }^{2}$ and Shuang-Jiang Liu ${ }^{1}$ \\ ${ }^{1}$ State Key Laboratory of Microbial Resource, Institute of Microbiology, Chinese Academy \\ of Sciences, Beijing 100101, China \\ ${ }^{2}$ Beijing Genomics Institute, Chinese Academy of Sciences, Beijing 101300, China
}

Comamonas sp. strain CNB-1, a chloronitrobenzene-degrading bacterium, was demonstrated to possess higher arsenate tolerance as compared with the mutant strain CNB-2. pCNB1, a plasmid harboured by CNB-1 but not CNB-2, contained the genetic cluster $\operatorname{ars}(R P B C)_{\text {Com, }}$, which putatively encodes arsenate-resistance regulator, family II arsenate reductase, arsenite efflux pump and family I arsenate reductase, respectively, in Comamonas strain CNB-1. The arsCnegative Escherichia coli could gain arsenate resistance by transformation with ars $P_{\mathrm{Com}}$ or ars $\mathrm{C}_{\mathrm{Com}}$, indicating that these two genes might express functional forms of arsenate reductases. Intriguingly, when CNB-1 cells were exposed to arsenate, the transcription of ars $P_{\mathrm{Com}}$ and ars $\mathrm{C}_{\mathrm{Com}}$ was measurable by $\mathrm{RT}-\mathrm{PCR}$, but only $\mathrm{ArsP}_{\mathrm{Com}}$ was detectable at protein level. To explore the proteins responding to arsenate stress, CNB-1 cells were cultured with and without arsenate and differential proteomics was carried out by two-dimensional PAGE (2-DE) and MALDI-TOF MS. A total of 31 differential 2-DE spots were defined upon image analysis and 23 proteins were identified to be responsive specifically to arsenate. Of these spots, 18 were unique proteins. These proteins were identified to be phosphate transporters, heat-shock proteins involved in protein refolding, and enzymes participating in carbon and energy metabolism.

\section{INTRODUCTION}

Arsenate is toxic to living cells by mimicking the function of phosphate and interrupts many biological processes such as protein phosphorylation (Carapito et al., 2006) and synthesis of phospholipids (Ordóñez et al., 2005). In many organisms, cells detoxify arsenate by an arsenate-resistance system (ARS). This ARS includes a reductase that reduces arsenate to arsenite, which is subsequently extruded from cells. The prokaryotic arsenate reductases can be classified into two families (and the eukaryotic arsenate reductase represents the third family): family I arsenate reductases need glutaredoxin as the source of reducing equivalents, and are represented by the ars $C$ products from Escherichia coli plasmid R773 (Chen et al., 1986) and some other Gram-negative bacteria. Family II arsenate reductases need thioredoxin as the source of reducing equivalents and are structurally related to low-molecular-mass protein tyrosine phosphatases. Examples of the family II arsenate reductases are the arsC products of Staphylococcus aureus and Bacillus

Abbreviations: ARS, arsenate-resistance system; 2-DE, two-dimensional PAGE; PMF, peptide mass fingerprint; RND, resistance-nodulation-cell division; TFA, trifluoroacetic acid..

Three supplementary figures are available with the online version of this paper. subtilis (Bennett et al., 2001; Ji \& Silver, 1992) (a phylogentic tree indicating functionally identified and putative arsenate reductases is shown in supplementary Fig. S1, available with the online version of this paper).

$\operatorname{ars} C$ and other arsenate-resistance genes are usually found in one operon (the ars operon) located on the chromosome or a plasmid. In the case of E. coli plasmids R773 and R46, the ars operon consists of five genes, arsR, $\operatorname{ars} D$, ars $A$, $\operatorname{ars} B$ and $\operatorname{ars} C$, that respectively encode arsenate-resistance regulator, arsenate chaperone, efflux pump subunit, arsenate permease and arsenate reductase (Chen et al., 1985; Bruhn et al., 1996). However, the ars operons of plasmids pI258 and pSX267 from Staphylococcus species (Ji \& Silver, 1992; Rosenstein et al., 1992) and of the E. coli chromosome (Diorio et al., 1995) consist of only three genes, $\operatorname{ars} R, \operatorname{ars} B$, and $\operatorname{ars} C$. Common to all ars operons are the genes $\operatorname{ars} R$, $\operatorname{ars} B$, and $\operatorname{ars} C$, which encode regulator, arsenite efflux pump and arsenate reductase, respectively (Rosen et al., 1988; San Francisco et al., 1990; Tisa \& Rosen, 1990; Wu \& Rosen, 1991; Gladysheva et al., 1994; Chen et al., 1986; Chen \& Rosen 1997).

After exposure to arsenate, the ars genes are transcribed and the corresponding proteins synthesized, leading to arsenate resistance (Wang et al., 2006; Muller et al., 2007). More 
recently, enhanced expression of heat-shock proteins in the presence of arsenate was found in the acidophilic archaeon Ferroplasma acidarmanus by application of two-dimensional PAGE (2-DE) (Baker-Austin et al., 2007). Further, global analysis of cellular responses to arsenite revealed that arsenite exposure results in an oxidative-stress-like response in Pseudomonas aeruginosa (Parvatiyar et al., 2005).

Comamonas sp. strain CNB-1 was isolated from activated sludge and uses 4-chloronitrobenzene as sole carbon and energy source (Wu et al., 2005). Recently, plasmid pCNB1, encoding the 4-chloronitrobenzene degradation pathway was sequenced, and analysis of the nucleotide sequence revealed several genes that are putatively involved in arsenate resistance (Ma et al., 2007). In this study, the arsenate resistance and global responses of strain CNB-1 to arsenate exposure were studied at genetic and proteomic levels.

\section{METHODS}

Bacterial strains, plasmids and growth conditions. The bacterial strains and plasmids used in this study are shown in Table 1.
Comamonas sp. strain CNB-1 was cultivated in Luria-Bertani (LB) medium with or without $100 \mathrm{mM}$ sodium arsenate. Cells were harvested after $24 \mathrm{~h}$ cultivation. All E. coli strains were cultivated aerobically at $37{ }^{\circ} \mathrm{C}$ in $\mathrm{LB}$ medium. When required, ampicillin was added to the medium at a final concentration of $100 \mu \mathrm{g} \mathrm{ml}^{-1}$.

DNA manipulation. Plasmid preparation, agarose gel electrophoresis, ligation and transformation were performed using standard methods (Sambrook et al., 1989). For pCNB1 isolation, a modified alkaline lysis method was used (Sinnett et al., 1998). PCR amplification of putative ars genes was performed with the primers described in Table 1. The PCR reaction was carried out with a Biometra thermocycler by using $P f u$ Taq DNA polymerase (Trans, Beijing, China) with an initial denaturation at $94{ }^{\circ} \mathrm{C}$ for $5 \mathrm{~min}$, followed by 30 cycles of denaturation $\left(40 \mathrm{~s}\right.$ at $94{ }^{\circ} \mathrm{C}$ ), an annealing step of $40 \mathrm{~s}$, and a $1-2$ min elongation step at $72{ }^{\circ} \mathrm{C}$. Annealing temperatures and elongation times were altered according to the GC content of primers and the size of targeted DNA fragments. PCR products were separated by agarose gel electrophoresis and further purified by using the agarose gel DNA fragment recovery kit (Tiangen, Beijing, China).

Determination of arsenate resistance by Comamonas sp. strain CNB-1 and complementation of $\boldsymbol{E}$. coli mutants. To test for growth of Comamonas sp. strain CNB-1 in the presence of

Table 1. Bacterial strains, plasmids and primers used in this study

\begin{tabular}{|c|c|c|}
\hline Strain, plasmid or primer & Description or primer sequence $\left(5^{\prime}-3^{\prime}\right)$ & Note or reference \\
\hline \multicolumn{3}{|l|}{ Comamonas sp. } \\
\hline CNB-1 & Isolated from activated sludge, assimilating $p$-chloronitrobenzene & Wu et al. (2005) \\
\hline CNB-2 & Mutant derived from strain CNB-1, devoid of pCNB1 & Wu et al. (2006) \\
\hline \multicolumn{3}{|l|}{ E. coli } \\
\hline WC3110 & E. coli W3110 lacking the arsenate reductase $(\Delta a r s C)$ & Mukhopadhyay et al. (2000) \\
\hline WC3110/pSE380-ars $C_{\text {Com }}$ & E. coli WC3110 containing pSE380-ars $C_{C o m}$ & This study \\
\hline WC3110/pSE380-arsP $P_{\text {Com }}$ & E. coli WC3110 containing pSE380-arsP $P_{\text {Com }}$ & This study \\
\hline AW3110 & E. coli W3110 lacking the ars operon $(\triangle \operatorname{arsRBC})$ & Carlin et al. (1995) \\
\hline AW3110/pSE380-ars $(B C)_{C o m}$ & E. coli AW3110 containing pSE380-ars $(B C)_{C o m}$ & This study \\
\hline AW3110/pSE380-ars $(P B)_{C o m}$ & E. coli AW3110 containing pSE380-ars $(P B)_{C o m}$ & This study \\
\hline \multicolumn{3}{|c|}{ Plasmids } \\
\hline pSE380 & $\mathrm{Ap}^{\mathrm{r}}, \operatorname{lacl}^{\mathrm{q}}$, pUC origin, expression vector & Lin et al. (2006) \\
\hline pSE380-ars $C_{C o m}$ & $\mathrm{Ap}^{\mathrm{r}}, \mathrm{pSE} 380$ containing $\operatorname{ars} C_{\mathrm{Com}}$ & This study \\
\hline pSE380-arsP $P_{\text {Com }}$ & $\mathrm{Ap}^{\mathrm{r}}, \mathrm{pSE} 380$ containing $\operatorname{ars}_{\text {Com }}$ & This study \\
\hline pSE380-ars $(B C)_{C o m}$ & $\mathrm{Ap}^{\mathrm{r}}$, pSE380 containing $\operatorname{ars}(B C)_{C o m}$ & This study \\
\hline pSE380-ars $(P B)_{C o m}$ & $\mathrm{Ap}^{\mathrm{r}}, \mathrm{pSE} 380$ containing $\operatorname{ars}(P B)_{\mathrm{Com}}$ & This study \\
\hline \multicolumn{3}{|l|}{ Primers } \\
\hline $\mathrm{PF}$ & TAACCCGGGCCTGGCATGGCG (SmaI) & To construct pSE380-arsP $P_{\text {Com }}$ \\
\hline PR & CGCGGATCCGGGTGGTCTCATTTC (BamHI) & \\
\hline $\mathrm{CF}$ & TAACCCGGGCCCCATGAACGACA (SmaI) & To construct pSE380-ars $C_{\text {Com }}$ \\
\hline CR & CGCGGATCCGCTATTCTCACGTCACTG (BamHI) & \\
\hline BCF & CGCEGATCCGTGGAAGGCTGACATG (BamHI) & To construct pSE380-ars $(B C)_{C o m}$ \\
\hline BCR & GGCGAAGCTTCCATCCAGCTATTCTCA (HindIII) & \\
\hline $\mathrm{PBF}$ & CGCGGATCCCGCTGCTGAAAGCCTCG $($ BamHI) & To construct pSE380-ars $(P B)_{\text {Com }}$ \\
\hline PBR & GGCGAAGCTTCGGGGTTGTGGTAGA (HindIII) & \\
\hline PBRTF & GATGTAGAGGGCTCGGAGGA & $\begin{array}{l}\text { To amplify the } 584 \text { bp fragment } \\
\text { between } \operatorname{ars} P_{C o m} \text { and ars } B_{C o m}\end{array}$ \\
\hline PBRTR & CGCCCACTCGAAGAAGC & \\
\hline BCRTF & GTCAGGGACGCTATGGTCTACG & $\begin{array}{l}\text { To amplify the } 452 \mathrm{bp} \text { fragment } \\
\text { between } \operatorname{ars} B_{\text {Com }} \text { and } \operatorname{ars} C_{\text {Com }}\end{array}$ \\
\hline BCRTR & TCATCGCCCAGGCCCAGTTC & \\
\hline
\end{tabular}


arsenate, the strain was pre-cultured in LB broth for $24 \mathrm{~h}$ and this pre-culture was used to inoculate fresh LB medium containing different concentrations of sodium arsenate $(0-200 \mathrm{mM})$. Growth was monitored by measuring the $\mathrm{OD}_{600}$ with a spectrophotometer.

Complementation of arsenate resistance in E. coli mutants WC3110 and AW3110 was performed with newly constructed plasmids carrying the different ars genes from Comamonas sp. strain CNB-1, which were cloned in the vector pSE380 (Table 1). Growth of recombinant E. coli strains was determined in LB medium as described above for Comamonas sp. strain CNB-1. Expression of targeted ars genes was induced with $0.5 \mathrm{mM}$ IPTG and various concentrations of sodium arsenate. The E. coli cultures were incubated at $37^{\circ} \mathrm{C}$ and 160 r.p.m. for $24 \mathrm{~h}$.

RNA isolation and RT-PCR. For RNA isolation, Comamonas sp. strain CNB-1 was cultivated in LB broth containing $100 \mathrm{mM}$ sodium arsenate. Total RNA was isolated using Trizol reagent kit (Tiangen, Beijing, China) according to the manufacturer's instructions. The extracted RNA was dissolved in $50 \mu \mathrm{l}$ water. To eliminate any genomic DNA, this RNA preparation was incubated with $10 \mathrm{U}$ DNase and $40 \mathrm{U}$ RNase inhibitor (Takara, cat. no. D2310A) for $30 \mathrm{~min}$ at $37^{\circ} \mathrm{C}$. To obtain cDNAs, the above preparations $(8 \mu$ l, containing $2 \mu \mathrm{g}$ RNA) were mixed with $4 \mu \mathrm{l}$ of $10 \mu \mathrm{M}$ primer PBRTR for ars $P_{C o m}-a r s B_{C o m}$ or BCRTR for $\operatorname{ars} B_{C o m}-\operatorname{ars} C_{C o m}$ (Table 1) in final volumes of $12 \mu \mathrm{l}$. To facilitate reverse transcription, any RNA secondary structures were eliminated by incubation at $70{ }^{\circ} \mathrm{C}$ for $5 \mathrm{~min}$, and pairing between RNA templates and primers was stimulated by quickly placing the mixtures on ice. cDNAs were synthesized in reaction mixtures (total volume $21 \mu \mathrm{l}$ ) containing the above-prepared mixture $(12 \mu \mathrm{l}), 4 \mu \mathrm{l}$ reaction buffer (Promega), $1 \mu \mathrm{l}$ of $10 \mathrm{mM}$ dNTP, $1 \mu \mathrm{l}$ RNase inhibitor, $2 \mu \mathrm{l}$ of $0.5 \mathrm{mM} \mathrm{MgCl}_{2}$ and $1 \mu \mathrm{l}$ ImProm-II reverse transcriptase (Promega). The mixtures were incubated for $60 \mathrm{~min}$ at $42{ }^{\circ} \mathrm{C}$ and reaction was terminated by incubation at $70{ }^{\circ} \mathrm{C}$ for $15 \mathrm{~min}$. The cDNAs synthesized were used for amplification of ars $P B$ or ars $B C$ fragments with PCR. PCRs were carried out using Taq DNA polymerase (Promega) and primers PBRTF/PBRTR for ars $P_{\text {Com }}-$ ars $B_{\text {Com }}$ and BCRTF/BCRTR for $\operatorname{ars} B_{\text {Com }}$-ars $C_{\text {Com }}$, respectively (Table 1 ).

2-DE and image analysis. Comamonas sp. strain CNB-1 was first grown aerobically overnight in LB broth and then was inoculated into $100 \mathrm{ml}$ fresh LB broth with and without $100 \mathrm{mM}$ sodium arsenate for $24 \mathrm{~h}$. After harvest, the cells were washed twice with $50 \mathrm{mM}$ Tris/ $\mathrm{HCl}$ ( $\mathrm{pH} 7.4$ ) and resuspended in $1.2 \mathrm{ml}$ lysis buffer ( $8 \mathrm{M}$ urea, $4 \%$ CHAPS, $2 \%$ Bio-Lyte) followed by sonication on ice. The supernatant generated from centrifuging at $7000 \mathrm{~g}$ was collected and stored at $-20{ }^{\circ} \mathrm{C}$ for proteomic analysis. Protein concentration was determined by the Bradford method with BAS calibration daily (Bradford, 1976).

The protein extracts were treated with DNase I and RNaseA at final concentrations of $1 \mathrm{mg} \mathrm{ml}^{-1}$ and $0.25 \mathrm{mg} \mathrm{ml}^{-1}$, respectively, and at $4{ }^{\circ} \mathrm{C}$ for $30 \mathrm{~min}$. Approximately $300 \mu \mathrm{g}$ proteins was loaded onto the 2-DE system. Briefly, first-dimension IEF was performed on $13 \mathrm{~cm}$ pH 4-7 strips or $11 \mathrm{~cm}$ pH 6-11 strips. The strip gel (pH 4-7; GE Healthcare) was rehydrated overnight in rehydration solution $(8 \mathrm{M}$ urea, $4 \%$ CHAPS, 50 mM DTT, $0.5 \%$ IPG buffer $\mathrm{pH} \mathrm{4-7)} \mathrm{contain-}$ ing the samples. IEF was performed in Ettan IPGphor II (GE Healthcare) with a stepwise programme at $500 \mathrm{~V}$ for $1 \mathrm{~h}, 1000 \mathrm{~V}$ for $1 \mathrm{~h}$, and $8000 \mathrm{~V}$ for $55000 \mathrm{~V} \mathrm{~h}$. The strip gel (pH 6-11) was rehydrated overnight in modified buffer ( $8 \mathrm{M}$ urea, $4 \%$ CHAPS, $10 \%$ 2-propanol, $5 \%$ glycerol, $1.5 \%$ hydroxyethyldisulfide (HED) and $1 \%$ IPG buffer $\mathrm{pH}$ 6-11). IEF was carried out by the stepwise programme at $150 \mathrm{~V}$ for $0.5 \mathrm{~h}, 300 \mathrm{~V}$ for $3 \mathrm{~h}, 600 \mathrm{~V}$ for $2 \mathrm{~h}$, and $3500 \mathrm{~V}$ for $35000 \mathrm{~V}$ h. The IEF strips were consecutively equilibrated with reducing buffer containing $6 \mathrm{M}$ urea, $375 \mathrm{mM}$ Tris/ $\mathrm{HCl} \mathrm{pH} \mathrm{8.8,} \mathrm{30 \%}$ $(\mathrm{v} / \mathrm{v})$ glycerol, $2 \%(\mathrm{w} / \mathrm{v})$ SDS and $2 \%(\mathrm{w} / \mathrm{v})$ DTT for $15 \mathrm{~min}$, and with alkylating buffer containing $6 \mathrm{M}$ urea, $375 \mathrm{mM}$ Tris $/ \mathrm{HCl}$ $\mathrm{pH} 8.8,30 \%(\mathrm{v} / \mathrm{v})$ glycerol, $2 \%(\mathrm{w} / \mathrm{v})$ SDS and $2.5 \%(\mathrm{w} / \mathrm{v})$ iodoacetamide for $15 \mathrm{~min}$. The second-dimension electrophoresis was performed on a $13 \%$ polyacrylamide gel using an SE600 Ruby device (GE Healthcare), which was run at $15 \mathrm{~mA}$ per gel for $30 \mathrm{~min}$, and then at $30 \mathrm{~mA}$ per gel until the bromophenol blue dye front reached the gel bottom. The protein spots on the 2-DE gels were visualized with Coomassie blue R-250 (Bio-Rad). To enable statistical evaluation of 2-DE images, all the samples were run in triplicate.

The stained 2-DE gels were scanned using UMAX Powerlook 2100XL at a resolution of 400 d.p.i. Image analysis was performed with ImageMaster 2D Platinum 6.0 software (GE Healthcare). The relative volume (vol\%) for each spot was normalized with the total spot volume at each gel. Student's $t$-test was adopted to evaluate the significantly differential spots between the control and experimental gels $(P<0.05)$. A twofold change in the relative spot volumes was defined as the threshold for significant difference in these 2-DE spots.

Tryptic in-gel digestion. The differential 2-DE spots were carefully excised and destained overnight at $37{ }^{\circ} \mathrm{C}$ in a solution of $25 \%$ ethanol and $7 \%$ acetic acid. The gel particles were reduced with $10 \mathrm{mM}$ DTT in $25 \mathrm{mM}$ ammonium bicarbonate at $56{ }^{\circ} \mathrm{C}$ for $1 \mathrm{~h}$ and alkylated with $55 \mathrm{mM}$ iodoacetamide in $25 \mathrm{mM}$ ammonium bicarbonate in the dark at room temperature for $45 \mathrm{~min}$ in situ. After complete drying, the gel pieces were digested overnight at $37{ }^{\circ} \mathrm{C}$ in $2-3 \mu$ modified trypsin (10 $\mathrm{ng}^{-1} \mathrm{l}^{-1}$, sequencing grade; Roche Diagnostics). The digestion reaction was stopped by addition of trifluoroacetic acid (TFA) at a final concentration of $0.1 \%$.

Protein identification by MALDI-TOF/TOF MS. One microlitre of the digestive mixture was loaded on an Anchorchip target (Bruker Dalton) and allowed to dry completely. Then $0.1 \mu \mathrm{l}$ matrix solution ( $4 \mathrm{mg} \mathrm{ml}^{-1} \alpha$-cyano-4-hydroxycinnamic acid, CHCA) was added to the target and mixed with the digested peptides. After washing with $0.1 \%$ TFA, the Anchorchip was delivered to MALDI-TOF/TOF MS for protein identification. Mass spectra and tandem mass spectra were obtained on an Ultraflex TOF/TOF mass spectrometer (Bruker Dalton). Positively charged ions were analysed in the reflector mode, using delayed extraction. The mass spectrometer was operated under $19 \mathrm{kV}$ accelerating voltage in the reflection mode and an $m / z$ range of 600-4000. Typically, 100 shots were accumulated per spectrum in MS mode and 400 shots in MS/MS mode. The spectra were processed using the FlexAnalysis 2.2 and BioTools 2.2 software tools.

Based upon mass signals, protein identification was performed using the Mascot software (http://www.matrixscience.com) to search the draft genome of Comamonas sp. strain CNB-1 on a local database, which was generated by shotgun approach. The draft genome contained 544 contigs. ORFs were predicted online by using the web version of the software GeneMarkS (http://exon.gatech.edu/ GeneMark/). The total predicted ORFs were formatted in FASTA and a specific protein database of strain CNB-1 was constructed. The mass signals were also taken for search against the NCBInr database with bacteria as taxonomy. The following parameters were used for database searches: monoisotopic mass accuracy $<100$ p.p.m., missed cleavages 1 , carbamidomethylation of cysteine as fixed modification, oxidation of methionine, N-terminal pyroglutamylation (peptide) and $\mathrm{N}$-terminal acetylation (protein) as variable modifications. In MS/MS mode, the fragment ion mass accuracy was set to $<0.7$ Da.

Sequence analysis. Multiple sequence alignment for arsenate reductases was performed with CLUSTAL_X (Jeanmougin et al., 1998) and sequence identity was calculated with BioEdit (Tippmann, 2004). 


\section{RESULTS}

\section{Bioinfomatic analysis of the ars operon orthologue on pCNB1 and growth of Comamonas sp. strain CNB-1 in the presence of arsenate}

A previous study revealed an ars operon orthologue on the plasmid pCNB1, which carried 4-chloronitrobenzene degradation genes in strain CNB-1 (Ma et al., 2007). Four genes, ars $R_{C o m}, a r s P_{C o m}, a r s B_{C o m}$ and $a r s C_{C o m}$, that were putatively involved in arsenate resistance were consecutively located on a putative transposon (Fig. 1a). Protein homology searches and sequence alignment indicated that (1) $\operatorname{ArsR}_{\text {Com }}$ had moderate sequence identities to the functionally identified ArsRs of Acidithiobacillus ferrooxidans (48\%) and Acidithiobacillus caldus (38\%); (2) $\mathrm{ArsB}_{\mathrm{Com}}$ had high identities to the ArsBs of E. coli R773 (73\%), P. aeruginosa (76\%), and A. ferrooxidans (64\%); (3) $\mathrm{ArsC}_{\mathrm{Com}}$ showed high sequence identities to the arsenate reductases belonging to family I, such as ArsCs in E. coli R773 (65\%), P. aeruginosa (80\%) and Sinorhizobium meliloti (71\%) (see also supplementary Fig. S1); (4) $\mathrm{ArsP}_{\mathrm{Com}}$, however, had significant sequence identity to the putative low-molecular-mass tyrosine phosphatases from Acidocorax sp. JS42 (73\%), P. aeruginosa (64\%), and Burkholderia multivorans (63\%) - it also showed moderate identities $(35.4-56.4 \%)$ to the family II arsenate reductases from Acidithiobacillus ferrooxidans, Acidithiobacillus caldus and Herminiimonas arsenicoxydans (see also supplementary Fig. S1); and (5) there were no ArsA, ArsD and ArsO homologues (Fig. 1b), which have been identified in other arsenate-resistant bacteria near the ars genetic cluster of strain CNB-1.

To determine whether Comamonas sp. CNB-1 is resistant to arsenate, it was cultivated in LB broth supplemented with various concentrations of arsenate. The results showed that CNB-1 significantly grew at $160 \mathrm{mM}$ arsenate (Fig. 2a). It was more resistant to arsenate than Mycobacterium smegmatis $(25 \mathrm{mM})$, Staphylococcus aureus $(50 \mathrm{mM}), B$. subtilis $(75 \mathrm{mM})$ and E. coli $(100 \mathrm{mM})$ (Ordóñez et al. 2005). The arsenate resistance of strain CNB-1 was clearly related to the occurrence of $\mathrm{pCNB} 1$ within cells. Compared to strain CNB-1, strain CNB-2, which had lost pCNB1, was less resistant but it retained some resistance $(\sim 60 \%$ growth at $60 \mathrm{mM}$ arsenate) (Fig. 2a). This result suggests that strain CNB-1 also has a chromosomic ars operon.

\section{$\operatorname{ars} P_{\text {com }}, a_{\text {rs }} B_{\text {com }}$ and ars $C_{\text {com }}$ confer increased resistance to arsenate in $E$. coli and $A_{\text {ss }} P_{\text {com }}$ represents a new arsenate reductase}

Based on BLAST searches and sequence alignment, $\operatorname{ars} B_{\text {Com }}$ and $\operatorname{ars}_{\mathrm{Com}}$ encode putative arsenite permease and

(a)

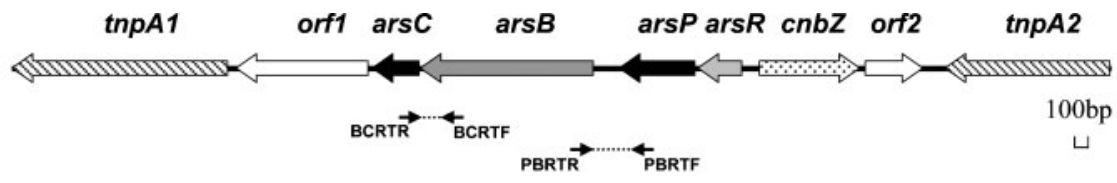

(b)
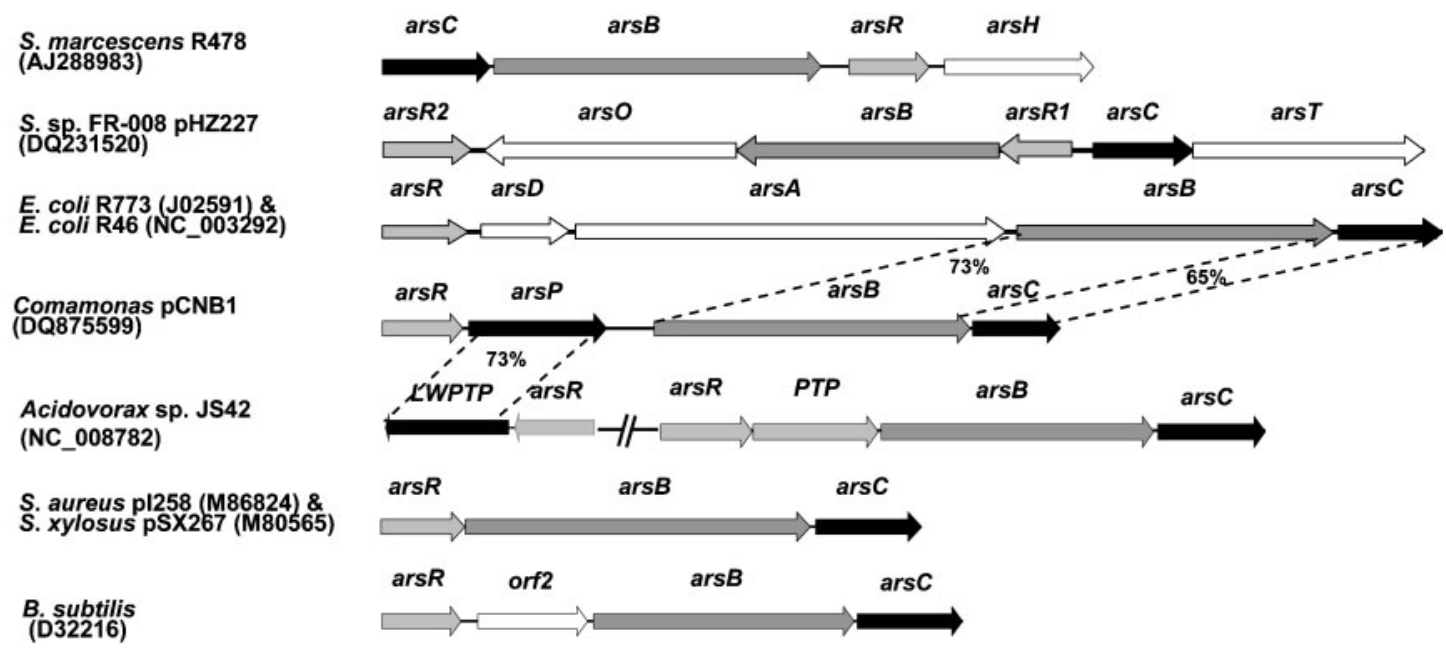

Fig. 1. (a) The ars genes of Comamonas sp. strain CNB-1 are flanked by putative transposases and form a putative ars operon. (b) Comparison of genetic organization of ars operons from various arsenate resistant bacterial strains. The accession numbers at NCBI of DNA sequences used are listed below the species names. The ars operon of strain CNB-1 encodes two arsenate reductases and these showed highest homology to their counterparts in plasmid R773 from E. coli and the putative lowmolecular-mass protein tyrosine phosphatase (LWPTP) of Acidovorax sp. JS42. 

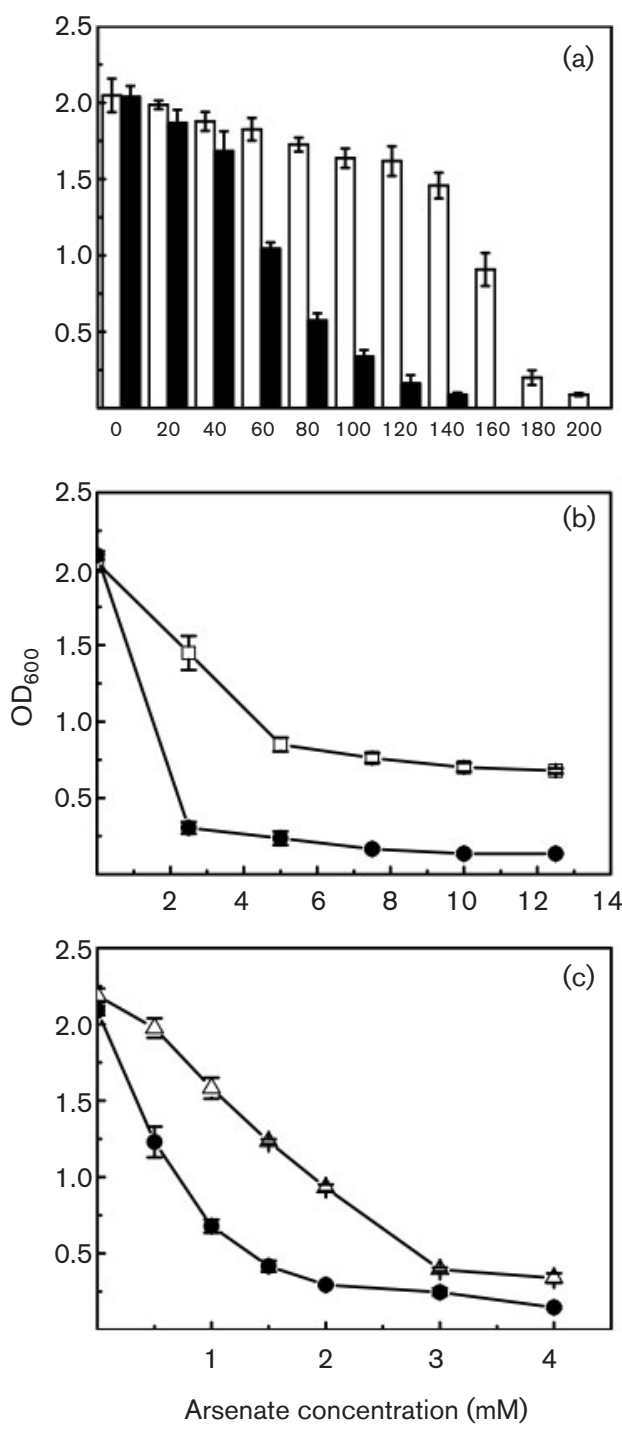

Fig. 2. (a) Growth of Comamonas sp. CNB-1 and CNB-2 in the presence of various concentrations of sodium arsenate. Cells were cultured in LB medium at $30{ }^{\circ} \mathrm{C}$ for $24 \mathrm{~h}$; open columns represent strain CNB-1, filled columns represent strain CNB-2. (b, c) Functional identification of the two arsenate reductases, $\operatorname{Ars}_{\mathrm{Com}}$ (b) and $\operatorname{ArsP}_{\mathrm{Com}}$ (c), in E. coli by complementation. Symbols are as follows: ๑, WC3110; $\square$, WC3110/pSE380-arsC Com; $\triangle$, WC3110/pSE380-ars $P_{\text {Com. }}$. Data were from three parallel experiments and standard deviations are indicated.

arsenate reductase, respectively; the function of $\operatorname{ars} P_{C o m}$ could not be clearly deduced. To test if the $\mathrm{ArsB}_{\mathrm{Com}}$ and $\mathrm{ArsC}_{\mathrm{Com}}$ are functional, E. coli mutants were complemented with these genes. The results indicated that $\operatorname{ars} C_{C o m}$ conferred arsenate resistance to E. coli WC3110, which is deficient in arsenate reductase (Fig. 2b). Furthermore, when the genes $\operatorname{ars} B_{C o m}$ and $\operatorname{ars} C_{C o m}$ were concomitantly cloned and expressed in the ars-operon-deficient E. coli AW3110, which is deficient in arsenate reductase and arsenite permease, the resulting strain had acquired resistance to arsenate (data not shown). These results support that the arsB $B_{C o m}$ and $\operatorname{ars} C_{C o m}$ of strain CNB-1 encode arsenite permease and arsenate reductase, respectively. Similarly, the gene $\operatorname{ars} P_{\mathrm{Com}}$ complemented arsenate resistance of E. coli WC3110, suggesting that $\mathrm{ArsP}_{\text {Com }}$ functioned as an arsenate reductase (Fig. 2c). Further, concomitant cloning of $\operatorname{ars}(P B)_{C o m}$ in E. coli AW3110 restored arsenate resistance (data not shown). The above results demonstrated that strain $\mathrm{CNB}-1$ has two arsenate reductases $\left(\mathrm{ArsC}_{\mathrm{Com}}\right.$ and $\left.\mathrm{ArsP}_{\mathrm{Com}}\right)$.

\section{ars $\boldsymbol{P}_{\text {com }}$ and ars $\boldsymbol{C}_{\mathrm{com}}$ are both transcribed in the presence of arsenate and belong to the same transcriptional unit}

To confirm that either $\operatorname{ars} P_{C o m}$ or $\operatorname{ars} C_{C o m}$ or both were functional during growth in the presence of arsenate, transcription of the two genes was examined by RT-PCR (primers used are indicated in Fig. 1a). The results clearly showed that both $\operatorname{ars} P_{C o m}$ and $\operatorname{ars} C_{C o m}$ are transcribed (Fig. 3a). Based on this result, it is proposed that $\operatorname{ars} P_{\text {Com }}$ (a)

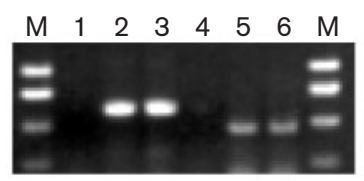

(c)

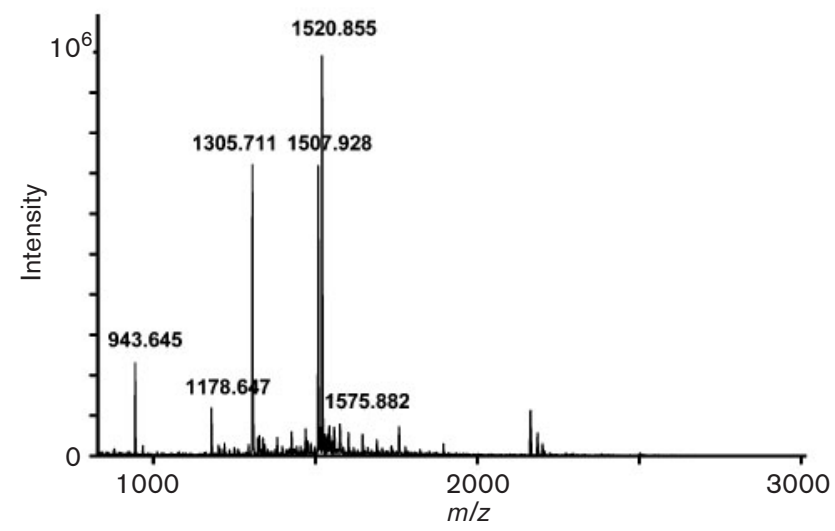

(b)

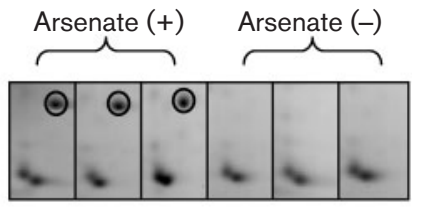

Fig. 3. (a) Transcript analysis of the putative ars operon of the plasmid pCNB1 from Comamonas sp. CNB-1, showing that both reductase genes ars $\mathrm{C}_{\mathrm{Com}}$ and $a r s P_{\mathrm{Com}}$ are transcribed in the presence of arsenate. Templates used for PCR were as follows: lanes 1 and 4, total RNA preparation; lanes 2 and 5, cDNAs from total RNA preparation; lanes 3 and 6, pCNB1. Primers for lanes 1 , 2 and 3 were PBRTF and PBRTR and for lanes 4,5 and 6 were BCRTF and BCRTR. The corresponding positions of primers are shown in Fig. 1(a). Lane M, DNA markers; bands from top to bottom represent 1000, 750, 500 and 250 bp. (b, c) Identification of ArsP $\mathrm{Com}_{\text {om }}$ from three 2-DE gels (b) and by MALDI-TOF MS (c). 
and $\operatorname{ars} C_{C o m}$ were transcribed and functional in the presence of arsenate. Moreover, RT-PCR products between $\operatorname{ars} P$ and $\operatorname{ars} B$ and between $\operatorname{ars} B$ and $\operatorname{ars} C$ were obtained (Fig. 3a), indicating that $\operatorname{ars} P$ and $\operatorname{ars} B$, and similarly $\operatorname{ars} B$ and $\operatorname{ars} C$, were cotranscribed. It is therefore concluded that $\operatorname{ars} P, \operatorname{ars} B$ and $\operatorname{ars} C$ belong to the same transcriptional unit (Fig. 1a).

\section{Proteome profiles of strain CNB-1 cells cultivated in the presence and absence of arsenate, and identification of differentially expressed proteins}

To investigate the global responses to arsenate stress, the proteomes of strain CNB-1 cells grown in the presence and absence of arsenate were separated by 2-DE. This was initially carried out with broad-range pH (3-10) IPG for protein IEF, and the results indicated few protein spots at lower $\mathrm{pH}(<4)$ but a large number of protein spots at neutral and higher $\mathrm{pH}$ (data not shown). In order to get better protein separation, two types of IPG gradient gels, covering $\mathrm{pH} \mathrm{4-7}$ and $\mathrm{pH}$ 6-11 respectively, were selected to separate protein samples. Under the conditions defined in this study (see Methods), there were $719 \pm 11(n=3)$ and $681 \pm 16(n=3)$ protein spots detected for cells grown with and without arsenate, respectively (2-DE gel images are available as supplementary Fig. S2, available with the online version of this paper). There were in total 31 proteins that either changed their abundances or were newly synthesized. Among them, 18 proteins were newly synthesized and seven proteins were increased significantly $(P<0.05)$ in abundance (2.5-6.1-fold, Table 2) for the arsenate-stressed proteome. In addition six proteins were decreased in abundance (2.4-3.9-fold) or disappeared in the arsenatestressed proteome.

The differentially expressed proteins were analysed by MALDI-TOF MS to obtain their peptide mass fingerprint (PMF). Attempts were made to identify those proteins by PMF matching and by using the tool MASCOT with the publicly available databases; only 10 proteins were identified. It is well known that protein identification based on PMF is highly dependent on the availability of genome data or protein sequence identity (Wilkins \& Williams, 1997). To improve the protein identification, a local dataset was established based on the draft genome sequence of strain CNB-1. By using this specific protein dataset, 23 proteins were identified (Table 2). Among those proteins, one protein, $\mathrm{ArsP}_{\text {Com }}$ (Fig. $3 \mathrm{~b}$ shows the results from three parallel experiments, and Fig. $3 \mathrm{c}$ indicates its PMF), was directly involved in arsenate resistance. Other proteins directly involved in arsenate resistance for strain CNB-1 were not detected on the 2-DE gels. Interestingly, more proteins involved in other cellular processes were significantly influenced in the presence of arsenate; these proteins are described below.

Stress response, protein refolding and ribosomal proteins. Heat-shock proteins that were newly synthesized or have their abundance increased in the presence of arsenate included DnaJ, DnaK (HSP70) and HSP20, which play an important role in protein refolding under stress conditions. Another protein involved in repair of damaged protein was glutathione $S$-transferase, which increased its abundance by 2.5 -fold. Three ribosomal proteins, S1, L1 and L3, decreased in abundance, suggesting that the protein synthesis process was affected in the presence of arsenate.

Carbohydrate metabolism and energy production. Other proteins identified included enzymes involved in carbohydrate metabolism and the glyoxylate cycle. In the presence of arsenate, enolase increased by 4.8 -fold. Enolase is a glycolytic enzyme catalysing the formation of phosphoenolpyruvate from 2-phosphoglycerate, the second of two high-energy intermediates that generate ATP in glycolysis. It was also found that a subunit of ubiquinolcytochrome $c$ reductase, which is involved in oxidative phosphorylation and leads to ATP generation, decreased by 2.8-fold (Table 2). Maintenance of energy (ATP) in a cell is critical for cell growth and proliferation; this study found that the enzymes involved in substrate-level phosphorylation increased but oxidative phosphorylation decreased when Comamonas strain CNB-1 grew in the presence of arsenate. Malate synthase G, an important characteristic enzyme of the glyoxylate cycle, was newly synthesized in the presence of arsenate. It is an enzyme catalysing the reversible condensation of glyoxylate with acetyl-CoA and water to form malate and CoA. The expression of malate synthase $G$ enabled the cell to use acetyl-CoA to generate increased levels of TCA cycle intermediates available for cells.

Membrane transport system. There were three induced proteins that were components of the membrane transporter system. They were the outer-membrane lipoprotein of the RND efflux system, the periplasmic phosphate-binding protein of the phosphate $\mathrm{ABC}$ transporter, and the extracellular solute-binding protein, respectively, indicating that the occurrence of arsenate in culture broth had an impact on the membrane transporter system.

\section{DISCUSSION}

In this study, a new genetic organization of the ars operon has been found on plasmid pCNB1 of Comamonas sp. strain CNB-1. Compared to previously reported ars operons (Chen et al., 1986; San Francisco et al., 1990; Wu \& Rosen, 1991; Chen \& Rosen 1997; Wang et al., 2006; Muller et al., 2007), the unique property of this ars operon from pCNB1 lies in that the ars operon has a total of four genes, namely ars $R_{C o m}$, $\operatorname{ars} P_{C o m}, a r s C_{C o m}$ and $a r s B_{C o m}$, and that $\operatorname{ars} C_{C o m}$ and $\operatorname{ars} P_{C o m}$ encode two arsenate reductases. Genetic complementation with plasmids harbouring either $\operatorname{ars} C_{C o m}$ or ars $P_{C o m}$ in arsC-negative $E$. coli conferred arsenate resistance to the host cells, and RT-PCR revealed 
Table 2. Differentially expressed proteins in cells grown on LB medium in the presence and absence of $100 \mathrm{mM}$ arsenate, identified by MALDI-TOF MS

Spot numbers are labelled in supplementary Fig. S2.

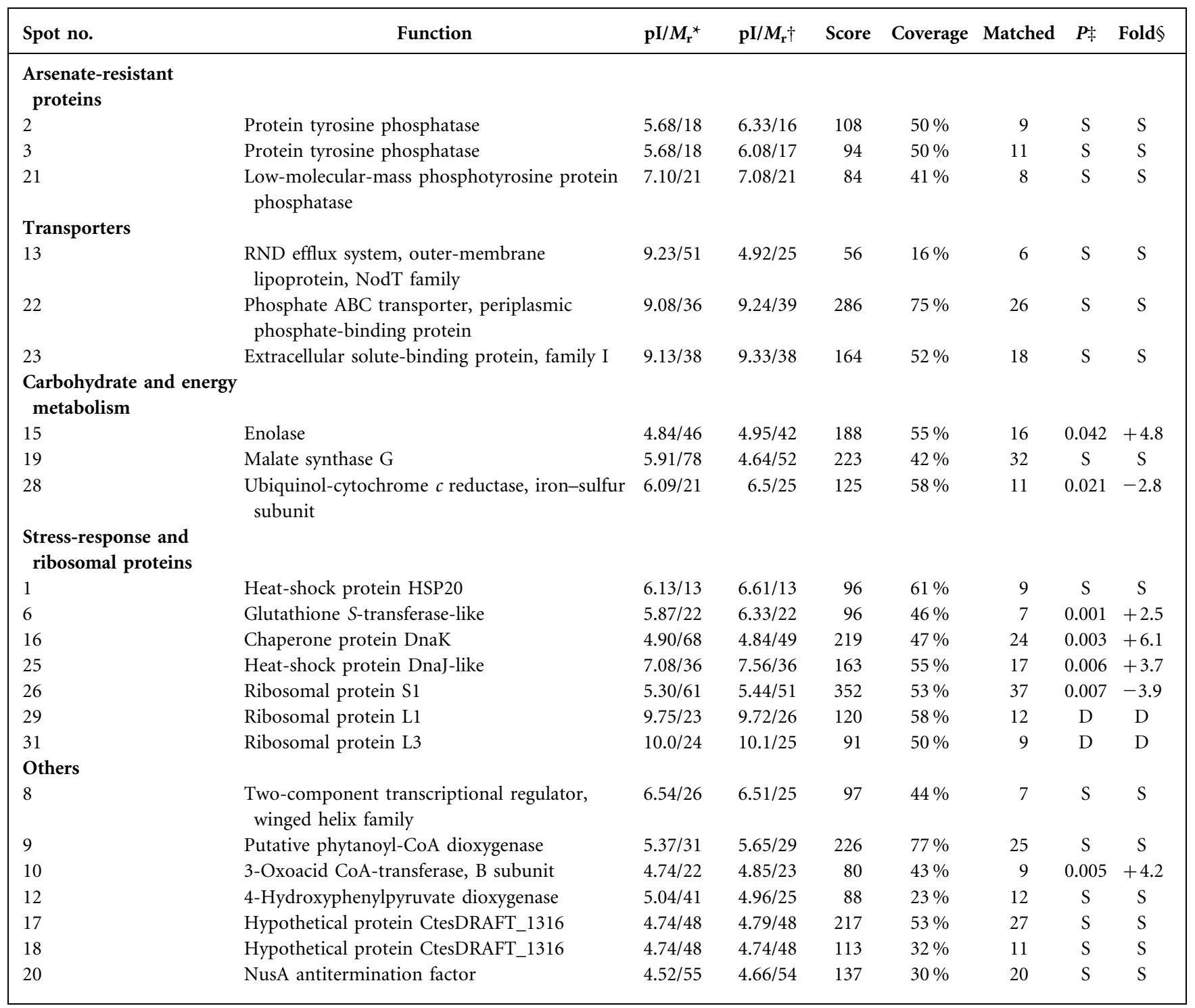

${ }^{\star}$ Theoretical values from the MASCOT search; $M_{\mathrm{r}}$ values are $\times 10^{-3}$.

$\dagger$ Experimental values; $M_{\mathrm{r}}$ values are $\times 10^{-3}$.

$\ddagger P$ indicates the statistical significance $(<0.05)$. ' $\mathrm{S}$ ' indicates that the spot is only observed in the arsenate-stressed proteome gel sets; ' $\mathrm{D}$ ' indicates that the spot disappears in the arsenate-stressed proteome gel set and is only observed in the reference gels.

$\S$ Fold indicates the upregulated $(+)$ or downregulated $(-)$ multiple.

that both $\operatorname{ars} C_{C o m}$ and $\operatorname{ars} P_{C o m}$ were transcribed in the presence of arsenate. Although only ArsP $\mathrm{P}_{\mathrm{Com}}$ was detected from the proteome of cells exposed to arsenate, expression of $\operatorname{ars} C_{\text {Com }}$ could not be excluded. In fact, a careful comparison of the proteomic gel images obtained from cells grown with and without arsenate revealed two spots that specifically appeared in the presence of arsenate; the $\mathrm{pI} / M_{\mathrm{r}}$ of the two spots were determined to be $6.02 / 15000$ and $5.71 / 13000$, which were close to the theoretical values $(6.04 / 13282 \mathrm{Da})$ of $\mathrm{ArsC}_{\mathrm{Com}}$. But identification of the two spots with MALDI-TOF MS failed. ArsC $\mathrm{C}_{\text {Com }}$ is homologous and phylogenetically related to the family I arsenate reductases that use glutaredoxin as electron donor and were previously identified in bacteria (Chen et al., 1986; Ji \& Silver, 1992; Rosen, 2002), and $\mathrm{ArsP}_{\text {Com }}$ is phylogenetically related to the family II arsenate reductases that use thioredoxin as electron donor. Very recently, two genes, ars $\mathrm{Ca}$ (annotated as arsenate reductase) and $\operatorname{ars} C b$ (annotated as arsenate efflux), that are located on the Herminiimonas arsenicoxydans genome and homologous to $\operatorname{ars} C_{C o m}$ and $\operatorname{ars} P_{C o m}$ respectively, 
have been reported (Muller et al., 2007), but they were not physiologically identified. Our experimental results clearly indicated that both $\mathrm{ArsP}_{\mathrm{Com}}$ and $\mathrm{ArsC}_{\mathrm{Com}}$ restored arsenate resistance of ArsC-negative E. coli, and they also showed significant difference in the level of arsenate resistance. $\mathrm{ArsC}_{\mathrm{Com}}$ enabled the ArsC-negative E. coli to resist much higher levels of arsenate. More biochemical work is needed for a full characterization of the two arsenate reductases encoded by $\operatorname{ars} P_{\text {Com }}$ and $\operatorname{ars} C_{\text {Com }}$.

In addition to the synthesis of arsenate-resistance proteins, other cellular responses to exposure of arsenate were also observed in Comamonas strain CNB-1 and other prokaryote strains with the proteomic tools in this and previous studies (Carapito et al., 2006; Parvatiyar et al., 2005; BakerAustin et al., 2007) (a diagram showing all the cellular processes influenced by arsenate in strain CNB-1 is shown in supplementary Fig. S3, available with the online version of this paper). In the acidophilic Ferroplasma acidarmanus strain Fer1, synthesis of heat-shock proteins HSP60 and HSP70, which are involved in protein refolding, was enhanced when cells were exposed to arsenite [As(III)] (Baker-Austin et al., 2007). In P. aeruginosa, exposure to arsenite resulted in an oxidative-stress-like response (Parvatiyar et al., 2005). This current study has shown for the first time the cellular responses to arsenate $[\mathrm{As}(\mathrm{V})]$ of Comamonas strain CNB-1. The global response to arsenate in strain CNB-1 included the enhanced synthesis of proteins associated with arsenate resistance and detoxification $\left(\mathrm{ArsP}_{\mathrm{Com}}\right.$ and GST), phosphate transport (PstS), heat-shock response (DnaJ/DnaK/HSP20), and energy generation and carbon metabolism (malate synthase and enolase). Functions of these proteins in arsenate resistance by Comamonas CNB-1 are illustrated in Fig. S3. Different from the response to arsenite in $P$. aeruginosa (Parvatiyar et al., 2005), significant changes of proteins involved in oxidative stress-like response were not observed in Comamonas strain CNB-1 when exposed to arsenate. The DnaK/DnaJ chaperone system is essential for the recovery of stress-induced protein aggregates (Kedzierska, 2005); thus it was deduced that exposure to arsenate would caused significant protein misfolding in cells. The increased DnaK/DnaJ abundance would stimulate the recovery of the misfolded protein due to the arsenate/arsenite binding.

\section{ACKNOWLEDGEMENTS}

This work was supported by grants from the National Natural Science Foundation of China (30725001). The authors are grateful to Professor B. P. Rosen at Wayne University (USA) for providing $E$. coli strains WC3110 and AW3110, and vector PSE380.

\section{REFERENCES}

Baker-Austin, C., Dopson, M., Wexler, M., Sawers, R. G., Stemmler, A., Rosen, B. P. \& Bond, P. L. (2007). Extreme arsenic resistance by the acidophilic archaeon 'Ferroplasma acidarmanus' Fer1. Extremophiles 11, 425-434.
Bennett, M. S., Guan, Z., Laurberg, L. \& Su, X. D. (2001). Bacillus subtilis arsenate reductase is structurally and functionally similar to low molecular weight protein tyrosine phosphatases. Proc Natl Acad Sci U S A 98, 13577-13582.

Bradford, M. M. (1976). A rapid and sensitive method for the quantitation of microgram quantities of protein utilizing the principle of protein-dye binding. Anal Biochem 72, 248-254.

Bruhn, D. F., Li, J., Silver, S., Roberto, F. \& Rosen, B. P. (1996). The arsenical resistance operon of IncN plasmid R46. FEMS Microbiol Lett 139, 149-153.

Carapito, C., Muller, D., Turlin, E., Koechler, S., Danchin, A., Van Dorsselaer, A., Leize-Wagner, E., Bertin, P. N. \& Lett, M.-C. (2006). Identification of genes and proteins involved in the pleiotropic response to arsenic stress in Caenibacter arsenoxydans, a metalloresistant beta-proteobacterium with an unsequenced genome. Biochimie 88, 595-606.

Carlin, A., Shi, W., Dey, S. \& Rosen, B. P. (1995). The ars operon of Escherichia coli confers arsenical and antimonial resistance. J Bacteriol 177, 981-986.

Chen, Y. \& Rosen, B. P. (1997). Metalloregulatory properties of the ArsD repressor. J Biol Chem 272, 14257-14262.

Chen, C. M., Mobley, M. L. \& Rosen, B. P. (1985). Separate resistances to arsenate and arsenite (antimonate) encoded by the arsenical resistance operon of R factor R773. J Bacteriol 161, 758-763.

Chen, C. M., Misra, T. K., Silver, S. \& Rosen, B. P. (1986). Nucleotide sequence of the structural genes for an anion pump: the plasmidencoded arsenical resistance operon. J Biol Chem 261, 15030-15038.

Diorio, C., Cai, J., Marmor, J., Shinder, R. \& DuBow, M. S. (1995). An Escherichia coli chromosomal ars operon homolog is functional in arsenic detoxification and is conserved in gram-negative bacteria. J Bacteriol 177, 2050-2056.

Gladysheva, T. B., Oden, K. L. \& Rosen, B. P. (1994). Properties of the arsenate reductase of plasmid R773. Biochemistry 33, 7288-7293.

Jeanmougin, F., Thompson, J. D., Gouy, M., Higgins, D. G. \& Gibson, T. J. (1998). Multiple sequence alignment with CLUSTAL_X. Trends Biochem Sci 23, 403-405.

Ji, G. \& Silver, S. (1992). Regulation and expression of the arsenic resistance operon from Staphylococcus aureus plasmid pI258. J Bacteriol 174, 3684-3694.

Kedzierska, S. (2005). Role of Escherichia coli molecular chaperones in the protection of bacterial cells against irreversible aggregation induced by heat shock. Postepy Biochem 51, 146-153.

Lin, Y. F., Walmsley, A. R. \& Rosen, B. P. (2006). An arsenic metallochaperone for an arsenic detoxification pump. Proc Natl Acad Sci U S A 103, 15617-15622.

Ma, Y.-F., Wu, J.-F., Wang, S.-Y., Jiang, C.-Y., Zhang, Y., Qi, S.-W., Liu, L., Zhao, G.-P. \& Liu, S. J. (2007). Nucleotide sequence of plasmid pCNB1 from Comamonas sp. strain CNB-1 reveals novel genetic organization and evolution for 4-chloronitrobenzene degradation. Appl Environ Microbiol 73, 4477-4483.

Mukhopadhyay, R., Shi, J. \& Rosen, B. P. (2000). Purification and characterization of Acr2p the Saccharomyces cerevisiae arsenate reductase. J Biol Chem 275, 21149-21157.

Muller, D., Médigue, C., Koechler, S., Barbe, V., Barakat, M., Talla, E., Bonnefoy, V., Krin, E., Arsène-Ploetze, F. \& other authors (2007). A tale of two oxidation states: bacterial colonization of arsenic-rich environments. PLoS Genet 3, e53.

Ordóñez, E., Letek, M., Valbuena, N., Gil, J. A. \& Mateos, L. M. (2005). Analysis of genes involved in arsenic resistance in Corynebacterium glutamicum ATCC 13032. Appl Environ Microbiol 71, 6206-6215. 
Parvatiyar, K., Alsabbagh, E. M., Ochsner, U. A., Stegemeyer, M. A., Smulian, A. G., Hwang, S. H., Jackson, C. R., McDermott, T. R. \& Hassett, D. J. (2005). Global analysis of cellular factors and responses involved in Pseudomonas aeruginosa resistance to arsenite. J Bacteriol 187, 4853-4864.

Rosen, B. P. (2002). Biochemistry of arsenic detoxification. FEBS Lett 529, 86-92.

Rosen, B. P., Weigel, U., Karkaria, C. \& Gangola, P. (1988). Molecular characterization of an anion pump. The arsA gene product is an arsenite (antimonate)-stimulated ATPase. J Biol Chem 263, 3067-3070.

Rosenstein, R., Peschel, A., Wieland, B. \& Gotz, F. (1992). Expression and regulation of the antimonite, arsenite, and arsenate resistance operon of Staphylococcus xylosus plasmid pSX267. J Bacteriol 174, 3676-3683.

Sambrook, J., Fritsch, E. F. \& Maniatis, T. (1989). Molecular Cloning: a Laboratory Manual, 2nd edn. Cold Spring Harbor, NY: Cold Spring Harbor Laboratory.

San Francisco, M. J. D., Hope, C. L., Owolabi, J. B., Tisa, L. S. \& Rosen, B. P. (1990). Identification of the metalloregulatory element of the plasmid-encoded arsenical resistance operon. Nucleic Acids Res 18, 619-624.

Sinnett, D., Richer, C. \& Baccicher, A. (1998). Isolation of stable bacterial artificial chromosome DNA using a modified alkaline lysis method. Biotechniques 24, 752-754.
Tippmann, H. F. (2004). Analysis for free: comparing programs for sequence analysis. Brief Bioinform 5, 82-87.

Tisa, L. S. \& Rosen, B. P. (1990). Molecular characterization of an anion pump. The ArsB protein is the membrane anchor for the ArsA protein. J Biol Chem 265, 190-194.

Wang, L., Chen, S., Xiao, X., Huang, X., You, D., Zhou, X. \& Deng, Z. (2006). arsRBOCT arsenic resistance system encoded by linear plasmid pHZ227 in Streptomyces sp. strain FR-008. Appl Environ Microbiol 72, 3738-3742.

Wilkins, M. R. \& Williams, K. (1997). Cross-species protein identification using amino acid composition, peptide mass fingerprinting, isoelectric point and molecular mass: a theoretical evaluation. J Theor Biol 186, 7-15.

Wu, J. \& Rosen, B. P. (1991). The ArsR protein is a trans-acting regulatory protein. Mol Microbiol 5, 1331-1336.

Wu, J.-F., Sun, C.-W., Jiang, C.-Y., Liu, Z.-P. \& Liu, S.-J. (2005). A novel 2 -aminophenol 1,6-dioxygenase involved in the degradation of $4 \mathrm{CNB}$ by Comamonas strain CNB-1: purification, properties, genetic cloning and expression in Escherichia coli. Arch Microbiol 183, 1-8.

Wu, J.-F., Jiang, C.-Y., Wang, B.-J., Ma, Y.-F., Liu, Z.-P. \& Liu, S.-J. (2006). Novel partial reductive pathway for 4-chloronitrobenzene and nitrobenzene degradation in Comamonas sp. strain CNB-1. Appl Environ Microbiol 72, 1759-1765.

Edited by: H. L. Drake 